\title{
Perioperative Complications And Risk Factors In Degenerative Lumbar Scoliosis Surgery For Patients Older Than 70 Years Of Age
}

This article was published in the following Dove Press journal:

Clinical Interventions in Aging

\section{Jun-zhe Ding* \\ Chao Kong* \\ Xiang-yao Sun \\ Shi-bao Lu}

Orthopaedic Department, Xuanwu Hospital, National Center for Clinical Research of Geriatric Diseases, Beijing,

People's Republic of China

*These authors contributed equally to this work
Correspondence: Shi-bao Lu Xuanwu Hospital of Capital Medical University, No.45 Changchun Street, Beijing 100053, People's Republic of China Tel +86 I3910727070

Fax +86 I083I9864I

Email spinelu@I63.com
Study design: Multivariate analysis of retrospective registry data.

Objective: To report the perioperative complication in a large cohort of surgery for elderly degenerative lumbar scoliosis (DLS) patients and to analyze the risk factors.

Summary of background data: The perioperative complication rate and risk factors for patients with DLS remain unclear, especially in elderly population.

Methods: Between November 2015 and June 2018, 98 patients aged 70 or older with DLS received decompression and intervertebral fusion by one spine surgeon at Beijing Xuanwu Hospital. The medical history and comorbidities of all patients were recorded.

Results: The perioperative complication rate was $34.7 \%$ in all patients, $11.2 \%$ of all patients had major complications, and $31.6 \%$ had minor complications. The major complication most commonly seen was wound infection, and the most common minor complication was hypoproteinemia. Elderly patients $(>75)$ had longer hospital stays $(17.5 \pm 7.9)$ when compared to younger patients. Two risk factors of perioperative complications were chosen after binary logistic regression analysis: lower BMI and longer instrumented segments. The only risk factor for major complications was longer instrumented level ( $\geq 3$ ), and the only risk factor for minor complications was lower BMI.

Conclusion: Our findings indicate that in elderly patients with DLS, lower BMI is a risk factor for minor perioperative complication. Obesity is not a major problem in this population, on the contrary, BMI is a protective factor for perioperative complications. The risk factors for major perioperative complications in elderly patients with DLS are longer instrumented segments but not related to the number of decompression and intervertebral fusion levels. Preoperative comorbidities and advanced age were not associated to a higher perioperative complication rate in elderly patients. The perioperative complication rate in patients with DLS over 70 years of age is found to be acceptable with appropriate perioperative management.

Keywords: degenerative lumbar scoliosis, elderly patients, perioperative complication, risk factor

\section{Introduction}

Degenerative lumbar scoliosis (DLS) refers to three-dimensional spinal deformity in adult with coronal position greater than $10^{\circ}$ scoliosis without a history of preexisted scoliosis. ${ }^{1,2}$ DLS is normally seen in individuals over 40 years of age, and the incidence and prevalence increase with aging. The pathophysiology of DLS is associated with degenerative change, mainly attributed to asymmetrical degeneration of the intervertebral disc and facet joints. ${ }^{1}$ Patients with DLS often have low 
back pain (LBP) with or without neurological symptoms such as sciatica and intermittent claudication. ${ }^{3}$ DLS has become a more prominent health problem these years with a fast-growing elderly population and an increased demand for quality of life. ${ }^{1}$ Surgery may be the preferred treatment in elderly patients with DLS when conservative treatment is ineffective. ${ }^{4}$ Extended life expectancy has led to more elderly patients to accept surgical treatment. ${ }^{5}$ With advances in anesthesiology, surgical instruments, and techniques, surgery for elder patients with DLS has become safer. However, elderly patients usually have a higher number of preoperative comorbidities. Aging and more comorbidities have been reported to cause more complications. ${ }^{6,7}$ Moreover, due to longer operative time, larger amounts of blood loss, wider extent of surgery and longer hospital stay, elderly DLS patient may suffer a higher risk of perioperative complications. ${ }^{8-10}$

The works of literature describing the complications of surgery for elderly patients with DLS are few. Cho et al ${ }^{11}$ analyzed 47 patients with DLS undergoing posterior fusion and instrumentation, and there were 14 early perioperative complications with 1 case of mortality by pulmonary embolism. Palmisani et $\mathrm{a}^{12}$ summarized 36 DLS patients treated operatively, and the overall perioperative complication rate was $19.4 \%$. A multicenter retrospective study of 256 patients with spinal deformity showed that elderly patient population faced the greater risk of perioperative complications, with $71 \%$ of the complication rates in patients over 65 years of age. ${ }^{13}$ The risk factors for predicting surgical complications in patients with DLS remain unclear, especially in elderly population. The purpose of this study was to report the perioperative complication in a large cohort of decompression and fusion surgeries for elderly DLS patients and to analyze the risk factors.

\section{Materials And Methods}

\section{Patients Demographics}

Ninety-eight patients aged 70 or older with DLS received operative treatment by one spine surgeon at Beijing Xuanwu Hospital between November 2015 and June 2018. The inclusion criteria for the study were (1) patients with DLS (Cobb angle $>10^{\circ}$ ) who underwent decompression and intervertebral fusion with pedicle screw fixation; (2) patient age over 70 years old; and (3) detailed medical record data available. Exclusion criteria included: other types of scoliosis, spinal trauma, spinal infection, and history of previous spinal surgery. Patient demographics, including age, gender, smoking status, height, weight, and body mass index (BMI), were collected through electronic medical record system. History of hypertension, diabetes, coronary heart disease, arrhythmia, osteoporosis, pulmonary disease, gastrointestinal disease, and kidney disease were considered as preoperative comorbidities. The medical history and comorbidities of all patients were recorded. Surgery records were examined to obtain the number of instrumented levels, intervertebral fusion levels, decompression levels, estimated blood loss, and operative time.

All patients had undergone decompression combined with intervertebral and posterolateral fusion with pedicle screw instrumentation at each relevant level. The patient received intravenous infusion of antibiotics until removal of the drainage tube. After the drainage tube is removed, daily dressing changes were performed. Compression stockings and early mobilization of the patients were utilized to prevent deep vein thrombosis. Routine blood tests and biochemical analyses were performed every other day after surgery until discharge or transfer.

Perioperative complications were categorized as minor and major complications as previously defined by Carreon et al. ${ }^{6}$ Major complications were defined as conditions that were life-threatening or may adversely affect the outcome of the treatment. Minor complications were defined as medical events noted in the medical records but did not compromise outcome.

The present study retrospectively extracted the patient's impact data without any intervention measures and patient consents are waived. The procedure performed in this study involving human participants was in accordance with the ethical standards of the institutional and/or national research committee at which the study was conducted (the ethics committee of Xuanwu Hospital of Capital Medical University Approval) and with the 1964 Helsinki declaration and its later amendments or comparable ethical standards.

\section{Statistical Analysis}

Statistical analysis was performed using IBM SPSS Statistics, version 22.0. (IBM Corp., Armonk, NY, USA). Continuous variables were analyzed using the Student's $t$-test or Mann-Whitney U-test, and categorical variables were analyzed using the Chi-squared test. $\mathrm{P}<0.05$ was considered significant. We then used binary logistic regression to analyze the risk factors for perioperative 
complications and used multiple logistic regression to analyze the risk factors for minor and major perioperative complications.

\section{Results}

\section{Patients Population}

In the present study, 98 DLS patients who were 70 years of age or older at the time of surgery were included. The average age was $77.6 \pm 5.0$ years $(70-88$ years). Among them, 27 patients $(27.6 \%)$ were male and $71(72.4 \%)$ were female. The average BMI was $25.2 \pm 3.5$ (17.6-33.2).

The most common comorbidity was hypertension, which was present preoperatively in $61.2 \%$ of the patients. Other common comorbidities include diabetes (16.3\%), coronary heart disease (15.3\%), hyperlipidemia $(9.2 \%)$, history of cerebral infarction (7.1\%), arrhythmia (6.1\%), osteoporosis $(8.2 \%)$, gastrointestinal diseases $(3.1 \%)$, renal diseases $(2.0 \%)$, pulmonary embolism $(2.0 \%)$, and rheumatoid arthritis $(2.0 \%)$. As high as $38.8 \%$ of all patients had one complication, $32.7 \%$ had two comorbidities, $7.1 \%$ had three comorbidities, $4.1 \%$ had four or more comorbidities, and $17.3 \%$ had no comorbidities. The breakdown of preoperative comorbidities is shown in Table 1.

The number of instrumented segments was distributed as follows: 1 segment 9.2\%, 2 segments $39.8 \%, 3$ segments $23.5 \%$, and 4 segments and above $27.5 \%$. The distribution of decompression level is: 1 level 18.4\%, 2 levels $43.9 \%, 3$ levels $24.5 \%$, and 4 levels and above $13.2 \%$. The number of intervertebral fusion levels was distributed as follows: 1 level 20.4\%, 2 levels 40.8\%, 3 levels $24.5 \%$, and 4 levels and above $14.3 \%$. The average number of instrumented segment was $3.17 \pm 1.95$, ranging from 1 to 9 segments; the average number of decompression level was $2.45 \pm 1.19$, ranging from 1 to 6 segments;

\section{Table I Breakdown Of Preoperative Comorbidities}

\begin{tabular}{|l|l|}
\hline Comorbidities & N (\%) \\
\hline Hypertension & $60(61.2 \%)$ \\
Diabetes & $16(16.3 \%)$ \\
Coronary heart disease & $15(15.3 \%)$ \\
Hyperlipidemia & $9(9.2 \%)$ \\
History of cerebral infarction & $7(7.1 \%)$ \\
Osteoporosis & $8(8.2 \%)$ \\
Arrhythmia & $6(6.1 \%)$ \\
Gastrointestinal diseases & $3(3.1 \%)$ \\
Renal diseases & $2(2.0 \%)$ \\
Pulmonary embolism & $2(2.0 \%)$ \\
Rheumatoid arthritis & $2(2.0 \%)$ \\
\hline
\end{tabular}

and the average number of intervertebral fusion level was $2.37 \pm 1.26$, ranging from 1 to 6 segments. The upper instrumented vertebra was $\mathrm{T} 8$ in 3 patients, $\mathrm{T} 9$ in 3 patients, T10 in 7 patients, T11 in 1 patient, L1 in 5 patients, L2 in 19 patients, L3 in 29 patients, L4 in 29 patients, and L5 in 2 patients. The lower instrumented vertebra was L2 in 1 patient, L3 in 2 patients, L4 in 5 patients, L5 in 36 patients, and the sacrum in 54 patients. The mean operative time was $256 \pm 99.2$ mins (80-664 mins) and the mean blood loss was $533 \pm 402.9 \mathrm{~mL}(100-$ $2000 \mathrm{~mL}$ ). The average hospital stay was $16 \pm 6.8$ days (9-65 days). The average preoperative Cobb angle was $19.5^{\circ} \pm 7.2^{\circ}\left(10.2^{\circ}-56.6^{\circ}\right)$ and was corrected to $6.4^{\circ} \pm 4.4^{\circ}$ $\left(0.2^{\circ}-22.4^{\circ}\right)$ immediately after surgery.

\section{Complication Rate And Risk Factor}

The perioperative complication rate was $34.7 \%$ in all patients, 11 patients $(11.2 \%)$ had major complications, and $31(31.6 \%)$ had minor complications. The major complication most commonly seen was wound infection, and the most common minor complication was hypoproteinemia. The contributions of complications are shown in Table 2.

Four patients had wound infections, and one of them underwent debridement. Two patients developed postoperative pulmonary infection. Postoperative neurological deficit was seen in 2 patients. One patient developed respiratory distress, myocardial infarction, congestive heart failure and was treated in intensive care unit of our hospital. Two patients underwent revision surgery during hospitalization due to cage malposition and epidural hematoma, respectively. No patient died during hospital stay.

Patients with and without perioperative complications are compared in Table 3 . The extent of surgery was divided into long segment $(\geq 3)$ and short segment $(<3)$. Patients with complications had lower BMI, longer instrumented segments and decompression levels, and longer hospital stays $(\mathrm{p} 1=0.005, \mathrm{p} 2=0.005, \mathrm{p} 3=0.023, \mathrm{p} 4=0.002$, respectively). There were no significant differences between the groups in terms of age, gender, smoking history, preoperative Cobb angle, comorbidities, and blood loss $(\mathrm{p}>0.05)$.

After comparing the two groups, three variables (BMI, number of instrumented segment, and decompression level) were included in the binary logistic regression analysis of risk factors for preoperative complication. Hospital stay was left out as an outcome variable. Two risk factors for perioperative complications were chosen after binary logistic regression analysis: lower $\mathrm{BMI}(\mathrm{OR}=0.226, \mathrm{CI}=$ 
Table 2 Perioperative Complication Contribution

\begin{tabular}{|c|c|c|c|}
\hline $\begin{array}{l}\text { Major } \\
\text { Complication }\end{array}$ & Complications & $\begin{array}{l}\text { Number Of } \\
\text { Patients }\end{array}$ & $\begin{array}{l}\text { Rate } \\
\text { (\%) }\end{array}$ \\
\hline & $\begin{array}{l}\text { Wound infection } \\
\text { Pneumonia } \\
\text { Myocardial } \\
\text { infarction } \\
\text { Congestive heart } \\
\text { failure } \\
\text { Epidural } \\
\text { hematoma } \\
\text { Neurological } \\
\text { deficit } \\
\text { Renal } \\
\text { insufficiency } \\
\text { Revision surgery } \\
\text { Respiratory } \\
\text { distress } \\
\text { Wound infection }\end{array}$ & $\begin{array}{l}4 \\
2 \\
1 \\
1 \\
1 \\
2 \\
1 \\
2 \\
1 \\
4\end{array}$ & $\begin{array}{l}4.1 \\
2.0 \\
1.0 \\
1.0 \\
1.0 \\
2.0 \\
1.0 \\
2.0 \\
1.0 \\
4.1\end{array}$ \\
\hline $\begin{array}{l}\text { Minor } \\
\text { complication }\end{array}$ & $\begin{array}{l}\text { Ileus } \\
\text { Urinary tract } \\
\text { infection } \\
\text { Instrument failure } \\
\text { Transient } \\
\text { arrhythmias } \\
\text { Intraoperative } \\
\text { dura tear } \\
\text { Hypoproteinemia } \\
\text { Delirium } \\
\text { Anemia } \\
\text { Electrolyte } \\
\text { imbalance } \\
\text { Urinary } \\
\text { incontinence }\end{array}$ & $\begin{array}{l}2 \\
4 \\
2 \\
2 \\
1 \\
24 \\
3 \\
6 \\
3 \\
1\end{array}$ & $\begin{array}{l}2.0 \\
4.1 \\
2.0 \\
2.0 \\
1.0 \\
24.5 \\
3.1 \\
6.1 \\
3.1 \\
1.0\end{array}$ \\
\hline
\end{tabular}

$0.086-0.594, \mathrm{p}=0.003)$ and longer instrumented segments $(\geq 3)(\mathrm{OR}=4.136, \mathrm{CI}=1.040-16.449, \mathrm{p}=0.044)$. The cutoff value of BMI is 25.32. The ROC curve predicting perioperative complications is shown in Figure 1.

\section{Risk Factors For Major And Minor Complications}

All variables were included in multiple logistic regression analysis. The result showed that longer instrumented level $(\geq 3)$ was the only risk factor for major complications (OR $=8.594, \mathrm{CI}=1.354-54.542, \mathrm{p}=0.023)$. The ROC curve predicting the probability of major complications during the perioperative period is shown in Figure 2. The only risk factor for minor complications was lower BMI $(\mathrm{OR}=$
Table 3 Characteristics Of Patients With And Without Perioperative Complications

\begin{tabular}{|c|c|c|c|}
\hline & $\begin{array}{l}\text { With } \\
\text { Complication }\end{array}$ & $\begin{array}{l}\text { Without } \\
\text { Complication }\end{array}$ & P-Values \\
\hline $\begin{array}{l}\text { Number of } \\
\text { patients }\end{array}$ & 34 & 64 & \\
\hline Mean age (yrs.) & $78 \pm 5.5$ & $78 \pm 4.9$ & 0.938 \\
\hline $\begin{array}{l}\text { Gender } \\
\text { Male } \\
\text { Female }\end{array}$ & $\begin{array}{l}8 \\
26\end{array}$ & $\begin{array}{l}19 \\
45\end{array}$ & 0.516 \\
\hline $\begin{array}{l}\text { History of } \\
\text { smoking } \\
\text { With } \\
\text { Without }\end{array}$ & $\begin{array}{l}6 \\
28\end{array}$ & $\begin{array}{l}7 \\
57\end{array}$ & 0.351 \\
\hline BMI & $24.1 \pm 2.86$ & $26.0 \pm 3.14$ & $0.005^{*}$ \\
\hline Cobb angle & $20.9 \pm 8.41$ & $18.8 \pm 6.47$ & 0.181 \\
\hline Surgical time (min) & $264 . I \pm 80.3$ & $255.2 \pm 105.6$ & 0.889 \\
\hline Blood loss (mL) & $592.5 \pm 447.4$ & $500.8 \pm 376.9$ & 0.286 \\
\hline $\begin{array}{l}\text { Instrumented } \\
\text { segment } \\
\qquad \begin{array}{l}<3 \\
\geq 3\end{array}\end{array}$ & $\begin{array}{l}7 \\
27\end{array}$ & $\begin{array}{l}32 \\
32\end{array}$ & $0.005^{*}$ \\
\hline $\begin{array}{l}\text { Decompression } \\
\text { level } \\
\qquad<3 \\
\quad \geq 3\end{array}$ & $\begin{array}{l}12 \\
22\end{array}$ & $\begin{array}{l}38 \\
26\end{array}$ & $0.023^{*}$ \\
\hline $\begin{array}{l}\text { Number of } \\
\text { comorbidities } \\
\text { No } \\
1 \\
2 \\
3 \\
>3\end{array}$ & $\begin{array}{l}6 \\
11 \\
14 \\
2 \\
1\end{array}$ & $\begin{array}{l}11 \\
26 \\
21 \\
5 \\
1\end{array}$ & 0.678 \\
\hline Hospital stay (ds) & $19.3 \pm 9.3$ & $15.0 \pm 4.2$ & $0.002 *$ \\
\hline
\end{tabular}

Notes: Statistical analyses regarding p-values were performed between the patient groups with and without perioperative complications. $* \mathrm{P}<0.05$.

0.815, CI $=0.696-0.955, \mathrm{p}=0.012$ ). The ROC curve predicting the probability of minor complications during the perioperative period is shown in Figure 3.

\section{Comparison Of Elderly Patients (>75) And Younger ( $\leq 75)$}

All patients were divided into a younger group $(\leq 75)$ and an elderly group $(>75)$. Comparison of the two groups is shown in Table 4 . The mean age of the younger group and 


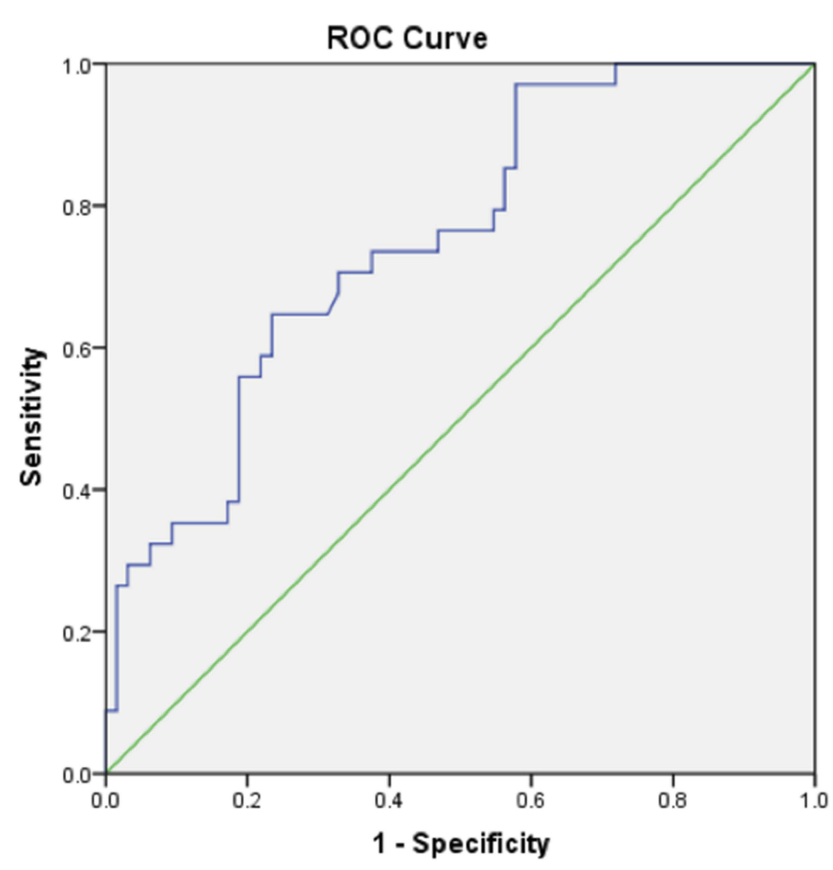

Diagonal segments are produced by ties.

Figure I ROC curve of risk factors predicting perioperative complications. The AUC was $0.75 \mathrm{II}$.

Abbreviations: ROC, receiver operator curve; AUC, area under the curve.

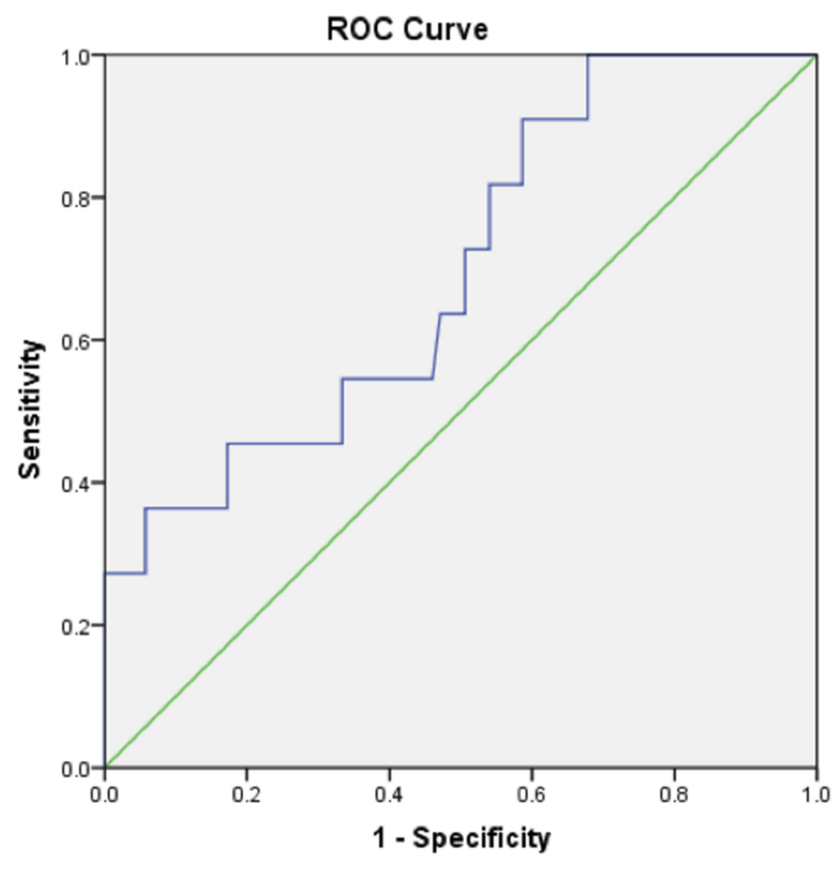

Diagonal segments are produced by ties.

Figure 2 ROC curve of risk factors (instrumented segments) predicting major perioperative complications. The AUC was 0.6964 .

Abbreviations: ROC, receiver operator curve; AUC, area under the curve.

the elderly group was $72 \pm 1.6$ and $81 \pm 3.1(\mathrm{p}<0.001)$, respectively. Elderly patients had longer hospital stays

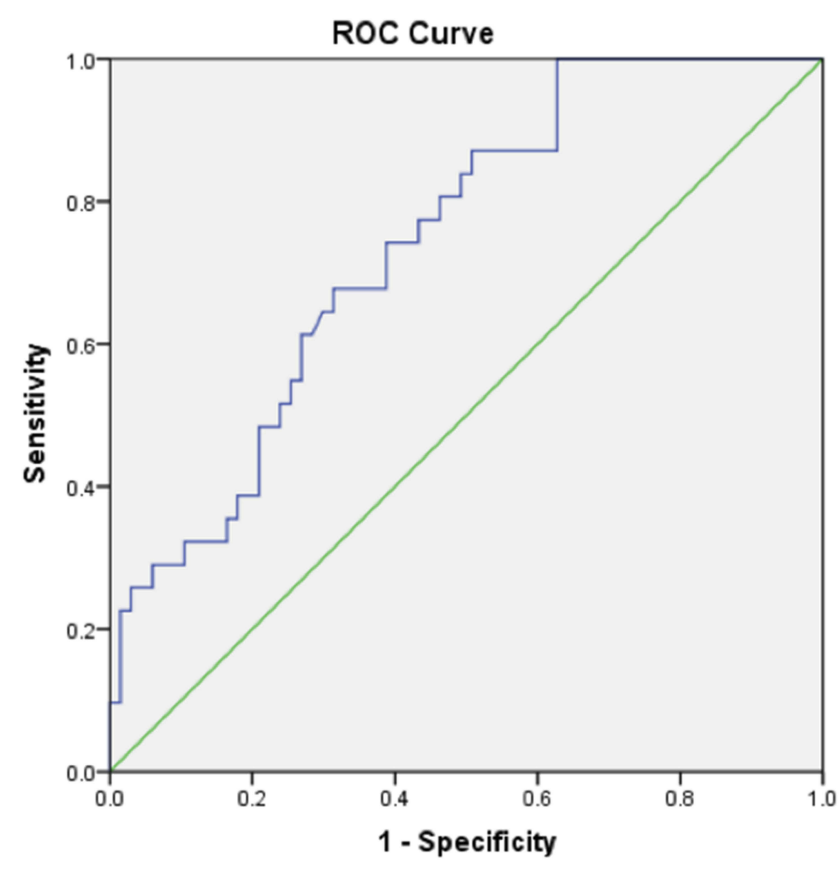

Diagonal segments are produced by ties.

Figure 3 ROC curve of risk factors (BMI) predicting minor perioperative complications. The AUC was 0.7407 .

Abbreviations: ROC, receiver operator curve; AUC, area under the curve; BMI, body mass index.

$(17.5 \pm 7.9)$ compared to younger patients $(14.8 \pm 3.8)$ $(\mathrm{p}=0.026)$. There were no significant differences in BMI, preoperative Cobb angle, the number of instrumented segment and decompression level, comorbidity, operative time, blood loss, and perioperative complications between the two groups $(\mathrm{P}>0.05)$.

\section{Discussion}

As the population ages, the number of elderly patients with DLS is increasing. Schwab et al ${ }^{14}$ reported that the prevalence of spinal deformity in people over 60 years of age as $68 \%$; of all hospitalized patients diagnosed with spinal deformity, $50 \%$ were 65 years of age and older. ${ }^{15}$ DLS is an important cause of low back pain, sciatica, and intermittent claudication in the elderly. ${ }^{16}$ Most patients with DLS received conservative treatment, but surgery for DLS has become more and more popular. Compared with younger patients, elderly patients usually have more severe spinal degeneration and combined with more comorbidities and less operation endurance. Elderly patients have been considered as a relative contraindication for DLS surgery. In recent years, with the advancement of anesthesiology and surgical techniques, DLS surgery has become safer and more extensive. ${ }^{17,18}$ However, DLS surgery in 
Table 4 Comparison Of Patients With Younger $(\leq 75)$ And Older (>75) Age

\begin{tabular}{|c|c|c|c|}
\hline & $70-75$ & $>75$ & P-Values \\
\hline Total patients & 38 & 60 & \\
\hline Mean age & $72 \pm 1.6$ & $8 I \pm 3.1$ & $<0.00 I^{*}$ \\
\hline \multicolumn{4}{|l|}{ Gender } \\
\hline Male & 9 & 18 & \\
\hline Female & 29 & 42 & 0.495 \\
\hline BMI & $25.8 \pm 2.83$ & $25.0 \pm 3.33$ & 0.179 \\
\hline Cobb angle & $20.1 \pm 8.19$ & $19.2 \pm 6.58$ & 0.532 \\
\hline \multicolumn{4}{|l|}{ Instrumented level } \\
\hline$<3$ & 17 & 25 & \\
\hline$\geq 3$ & 21 & 35 & 0.765 \\
\hline \multicolumn{4}{|l|}{ Decompression level } \\
\hline$<3$ & 23 & 30 & \\
\hline$\geq 3$ & 15 & 30 & 0.308 \\
\hline \multicolumn{4}{|l|}{ Comorbidities } \\
\hline no & 4 & 10 & \\
\hline I & 18 & 26 & \\
\hline 2 & 10 & 18 & \\
\hline 3 & 4 & 5 & \\
\hline$>3$ & 2 & I & 0.755 \\
\hline Surgical time & $245.8 \pm 78.5$ & $266.2 \pm 107.3$ & 0.314 \\
\hline Blood loss & $554.3 \pm 368.5$ & $511.8 \pm 425.7$ & 0.673 \\
\hline Hospital stay & $14.8 \pm 3.8$ & $17.5 \pm 7.9$ & $0.026 *$ \\
\hline \multicolumn{4}{|l|}{ Complication } \\
\hline With & 13 & 21 & \\
\hline Without & 25 & 39 & 0.936 \\
\hline
\end{tabular}

Notes: Statistical analyses regarding P-values were performed between the patient groups with and without perioperative complications. $* \mathrm{P}<0.05$.

the elderly is more skill-required and with high risk of complication. ${ }^{19,20}$ Also, compared with younger patients, elderly DLS patients generally have longer operative time, more blood loss, larger extent of surgery, and longer hospital stay. ${ }^{2}$ The incidence and distribution of perioperative complications as well as their risk factors could be inconsistent with younger patients. There were few studies of surgical complications in elderly patients with DLS. Therefore, the present study analyzed the perioperative complications of patients with DLS over 70 years of age and discussed the risk factor in this elderly population.

The reported incidence of perioperative complications in patients with DLS has been inconsistent. Li et $\mathrm{al}^{21}$ studied 34 scoliosis patients over 65 years of age and the complication rate was $17 \%$. Perioperative complications include postoperative neurological deficits, myocardial infarction, and reoperation. Cho et $\mathrm{al}^{9}$ assessed complications after posterior fusion and instrumentation for DLS and determined abundant blood loss as a significant risk factor for early perioperative complications. However, the assessment was conducted in a rather younger patient population with an average age of 66.6 years. Also, their patient group had a much larger amount of blood loss of $2106 \pm 1083 \mathrm{~mL}$ (range $600-6000 \mathrm{~mL}$ ) compared with the present study. Excessive blood loss can seriously affect the general condition of the patients and become a risk factor for perioperative complications. In contrast, the relatively small amount of blood loss did not have a significant impact on the perioperative condition of elderly patients in the present study. Drazin et $\mathrm{al}^{22}$ summarized the complications of spinal deformity surgery in elderly patients. A total of 311 complications were reported in 14 studies involving 815 patients, with a total complication rate of $38 \%$. Among them, 13 studies reported an average mortality of $0.85 \%$. Dural tear is the most common complication, accounting for $5.5 \%$. Other common complications include wound infection $(5.25 \%)$, pulmonary $(5 \%)$, renal (4.7\%), neurological (4.7\%), gastrointestinal (4.5\%), and cardiac (3.7\%) complications. Most of the previous studies used a binary system defined by Carreon et al. ${ }^{6}$ Perioperative complications were divided into major and minor complications. The present study applied the same classification.

The overall perioperative complication rate was $34.7 \%$; $11.2 \%$ of the patients had major complications and $31.6 \%$ had minor complications according to our result. The most common major complication was wound infection (4.1\%), and the most common minor complication was hypoproteinemia $(24.5 \%)$. The reported incidence of wound infection of lumbar spine surgery in patients over 70 years of age was $1-12 \% .^{6,8,23-26}$ Dubory et al reported that age, preoperative diabetes, and operative time over 3 hours were the risk factors for surgical site infection in a multicenter study. ${ }^{27}$ Elderly patients generally have decreased metabolic rate, decreased circulatory function, lower immunity, poor nutritional status, and comorbidities such as diabetes, which leads to a higher risk of wound infection. Longer operative time of DLS surgery increases the probability of contamination of the surgical field and surgical instruments, especially in posterior lumbar fusion surgery. ${ }^{27}$ Also, the use of microscopy and intraoperative radiographic inspection increases the risk of bacterial colonization. $^{28}$ The hospital stay of DLS patients is 
prolonged due to more recovery and functional exercise time. Therefore, the risk of postoperative wound infection increases as hospital is a high-risk environment of infection. The most common minor complication is hypoproteinemia. The metabolic rate, nutrient intake, and compensative capacity are mostly declined in patients over 70 years of age, which could be the causes of postoperative hypoproteinemia.

In the present study, the BMI and number of instrumented segments were risk factors for postoperative complications. After analyzing major and minor complications, the number of instrumented segments is the risk factor for major complications and lower BMI is the risk factor for minor complications. Previous studies showed that obese patients have a higher incidence of complications. ${ }^{29-31}$ However, the present study showed a different result. The patient population in our study was over 70 years of age and the average BMI was $25.2 \pm 3.5$, which did not reach the obesity range. For elderly population, a lower BMI indicates poorer compensate capacity and more prone to postoperative malnutrition and hypoproteinemia. Postoperative malnutrition status was reported to be a risk factor for other perioperative complication such as wound infection, which leads to a higher total complication rate. ${ }^{32,33}$ More instrumented segments correspond to larger surgical wounds, more blood loss, longer operative time, more postoperative recovery time, and longer hospital stay. Conversely, less surgical trauma is beneficial for early postoperative exercise and reduces complications caused by prolonged bed rest, such as pulmonary embolism, pulmonary infection, urinary tract infection, ileus, deep venous thrombosis, and delirium.

The impact of comorbidities on perioperative complications remains controversial. Previous studies showed that preoperative comorbidity is a risk factor for perioperative complications. ${ }^{7,25,34}$ However, other studies reported that comorbidities are not associated with postoperative complications. ${ }^{6,10,35}$ In the present study, no association was found between the number of preoperative comorbidities and perioperative complications. Advances in perioperative care and preoperative evaluation may explain the difference. The general condition evaluation and management of patients are routine procedures, and most of the comorbidities are satisfactorily managed preoperatively.

There is controversy about whether the incidence of surgical complications in elderly lumbar patients is increased with age. Some studies reported that the incidence of perioperative complication in the elderly was not significantly higher than those younger patients. ${ }^{10,23,24,36-39}$ Okuda et al ${ }^{36}$ studied 101 patients with lumbar spondylolisthesis undergoing lumbar decompression and fusion. The overall complication rate was $16 \%$ and $13 \%$ in patients over 70 years of age and under 70 years of age. Arinzon et $\mathrm{al}^{37}$ indicated that the overall complication rate was similar in elderly patients over 75 years of age and those under 75 years of age in their study, $41 \%$ and $47 \%$, respectively. However, other studies reported a higher incidence of complications in elderly patients. $^{6-8}$ Deyo et $\mathrm{al}^{40}$ reported that the morbidity and mortality increased with aging. Carreon et $\mathrm{al}^{6}$ followed 98 elderly patients over 65 years of age who underwent lumbar decompression and arthrodesis. Total perioperative complication rate was $80 \%$. The incidence of major complications in patient group aged 65-69 and 70-74 years was $14.3 \%$ and $13.3 \%$, respectively; the incidence of minor complications was also similar $(82.7 \%$ and $76.5 \%$, respectively). However, the incidence of major complications in patient group over 75 years of age significantly increased to $49 \%$. According to the result of the present study, there was no significant difference in the perioperative complication rate between elderly patients and young patients. Strict operative indications and preoperative management of DLS surgery may be one of the reasons. Patients who are prone to complications are excluded from surgical procedures since DLS surgery puts higher demands on the general condition of the patient, therefore patients over 75 years of age in our group may have a lower complication rate.

The present study has its limitations. First, the study is retrospective. Second, the study only included surgicaltreated patients with DLS who were over 70 years of age, which limited the number of patients involved. However, limited age range and specific types of spinal deformity could increase the persuasiveness of the study.

\section{Conclusion}

Our findings indicate that in elderly patients with DLS, lower BMI is a risk factor for minor perioperative complication. Obesity is not a major problem in this population, on the contrary, BMI is a protective factor for perioperative complications due to a lower nutritional reserve and compensative capacity of the elderly. Elderly patients with a BMI below 25.32 are more prone to perioperative complications after DLS surgery. The risk factors for major perioperative complications in elderly patients with DLS are longer instrumented segments $(\geq 3)$ but not related to the number of decompression levels. Preoperative comorbidities and advanced age were not associated to a higher 
perioperative complication rate in elderly patient population. The perioperative complication rate in patients with DLS over 70 years of age is found to be acceptable with appropriate perioperative management.

\section{Disclosure}

The authors declared that they have no conflicts of interest in this work.

\section{References}

1. Wong E, Altaf F, Oh LJ, Gray RJ. Adult degenerative lumbar scoliosis. Orthopedics. 2017;40(6):e930-e939. doi:10.3928/0147744720170606-02

2. Aebi M. The adult scoliosis. Eur Spine J. 2005;14(10):925-948. doi:10.1007/s00586-005-1053-9

3. Fu KM, Rhagavan P, Shaffrey CI, Chernavvsky DR, Smith JS. Prevalence, severity, and impact of foraminal and canal stenosis among adults with degenerative scoliosis. Neurosurgery. 2011;69 (6):1181-1187. doi:10.1227/NEU.0b013e31822a9aeb

4. Akbarnia BA, Ogilvie JW, Hammerberg KW. Debate: degenerative scoliosis: to operate or not to operate. Spine (Phila Pa 1976). 2006;31 (19 Suppl):S195-201. doi:10.1097/01.brs.0000234732.43489.0f

5. Glassman SD, Carreon LY, Dimar JR, Campbell MJ, Puno RM, Johnson JR. Clinical outcomes in older patients after posterolateral lumbar fusion. Spine J. 2007;7(5):547-551. doi:10.1016/j.spinee.20 06.11 .003

6. Carreon LY, Puno RM, Dimar JR 2nd, Glassman SD, Johnson JR. Perioperative complications of posterior lumbar decompression and arthrodesis in older adults. $J$ Bone Joint Surg Am. 2003;85-a (11):2089-2092. doi:10.2106/00004623-200311000-00004

7. Raffo CS, Lauerman WC. Predicting morbidity and mortality of lumbar spine arthrodesis in patients in their ninth decade. Spine. 2006;31(1):99-103. doi:10.1097/01.brs.0000192678.25586.e5

8. Shabat S, Arinzon Z, Folman Y, et al. Long-term outcome of decompressive surgery for lumbar spinal stenosis in octogenarians. Eur Spine J. 2008;17(2):193-198. doi:10.1007/s00586-007-0514-8

9. Cho KJ, Suk SI, Park SR, et al. Complications in posterior fusion and instrumentation for degenerative lumbar scoliosis. Spine. 2007;32 (20):2232-2237. doi:10.1097/BRS.0b013e31814b2d3c

10. Ragab AA, Fye MA, Bohlman HH. Surgery of the lumbar spine for spinal stenosis in 118 patients 70 years of age or older. Spine (Phila Pa 1976). 2003;28(4):348-353. doi:10.1097/01.BRS.0000048494.66 599.DF

11. Cho KJ, Suk SI, Park SR, et al. Risk factors of sagittal decompensation after long posterior instrumentation and fusion for degenerative lumbar scoliosis. Spine (Phila Pa 1976). 2010;35(17):1595-1601. doi:10.1097/BRS.0b013e3181bdad89

12. Palmisani M, Dema E, Cervellati S. Surgical treatment of adult degenerative scoliosis. Eur Spine J. 2013;22(Suppl 6):S829-833. doi:10.1007/s00586-013-3012-1

13. Smith JS, Shaffrey CI, Glassman SD, et al. Risk-benefit assessment of surgery for adult scoliosis: an analysis based on patient age. Spine (Phila Pa 1976). 2011;36(10):817-824. doi:10.1097/BRS.0b013e31 $81 \mathrm{e} 21783$

14. Schwab F, Dubey A, Gamez L, et al. Adult scoliosis: prevalence, SF36 , and nutritional parameters in an elderly volunteer population. Spine (Phila Pa 1976). 2005;30(9):1082-1085. doi:10.1097/01.brs.00 00160842.43482.cd

15. Jo DJ, Jun JK, Kim KT, Kim SM. Lumbar interbody fusion outcomes in degenerative lumbar disease: comparison of results between patients over and under 65 years of age. $J$ Korean Neurosurg Soc. 2010;48(5):412-418. doi:10.3340/jkns.2010.48.5.412
16. Ploumis A, Transfledt EE, Denis F. Degenerative lumbar scoliosis associated with spinal stenosis. Spine J. 2007;7(4):428-436. doi:10. 1016/j.spinee.2006.07.015

17. Weinstein JN, Lurie JD, Olson PR, Bronner KK, Fisher ES. United States' trends and regional variations in lumbar spine surgery: 1992-2003. Spine (Phila Pa 1976). 2006;31(23):2707-2714. doi:10.1097/01.brs.0000248132.15231.fe

18. Nasser R, Yadla S, Maltenfort MG, et al. Complications in spine surgery. J Neurosurg Spine. 2010;13(2):144-157. doi:10.3171/2010. 3.SPINE09369

19. Schwab FJ, Lafage V, Farcy JP, Bridwell KH, Glassman S, Shainline MR. Predicting outcome and complications in the surgical treatment of adult scoliosis. Spine (Phila Pa 1976). 2008;33(20):2243-2247. doi:10.1097/BRS.0b013e31817d1d4e

20. Baron EM, Albert TJ. Medical complications of surgical treatment of adult spinal deformity and how to avoid them. Spine (Phila Pa 1976). 2006;31(19 Suppl):S106-118. doi:10.1097/01.brs.0000232713.693 42.df

21. Li G, Passias P, Kozanek M, et al. Adult scoliosis in patients over sixty-five years of age: outcomes of operative versus nonoperative treatment at a minimum two-year follow-up. Spine (Phila Pa 1976). 2009;34(20):2165-2170. doi:10.1097/BRS.0b013e3181b3ff0c

22. Drazin D, Shirzadi A, Rosner J, et al. Complications and outcomes after spinal deformity surgery in the elderly: review of the existing literature and future directions. Neurosurg Focus. 2011;31(4):E3. doi:10.3171/2011.7.FOCUS11145

23. Jonsson B, Stromqvist B. Lumbar spine surgery in the elderly. Complications and surgical results. Spine (Phila Pa 1976). 1994;19 (13):1431-1435. doi:10.1097/00007632-199407000-00001

24. Vitaz TW, Raque GH, Shields CB, Glassman SD. Surgical treatment of lumbar spinal stenosis in patients older than 75 years of age. $J$ Neurosurg. 1999;91(2):181-185. doi:10.3171/spi.1999.91.2.0181

25. Acosta FL Jr., McClendon J Jr., O'Shaughnessy BA, et al. Morbidity and mortality after spinal deformity surgery in patients 75 years and older: complications and predictive factors. J Neurosurg Spine. 2011;15(6):667-674. doi:10.3171/2011.7.SPINE10640

26. Balabaud L, Pitel S, Caux I, et al. Lumbar spine surgery in patients 80 years of age or older: morbidity and mortality. Eur J Orthop Surg Traumatol. 2015;25(Suppl 1):S205-212. doi:10.1007/s00590-0141556-3

27. Dubory A, Giorgi H, Walter A, et al. Surgical-site infection in spinal injury: incidence and risk factors in a prospective cohort of 518 patients. Eur Spine J. 2015;24(3):543-554. doi:10.1007/s00586014-3523-4

28. Bible JE, O’Neill KR, Crosby CG, Schoenecker JG, McGirt MJ, Devin CJ. Microscope sterility during spine surgery. Spine (Phila Pa 1976). 2012;37(7):623-627. doi:10.1097/BRS.0b013e3182286129

29. Patel N, Bagan B, Vadera S, et al. Obesity and spine surgery: relation to perioperative complications. J Neurosurg Spine. 2007;6(4):291297. doi:10.3171/spi.2007.6.4.1

30. Onyekwelu I, Glassman SD, Asher AL, Shaffrey CI, Mummaneni PV, Carreon LY. Impact of obesity on complications and outcomes: a comparison of fusion and nonfusion lumbar spine surgery. $J$ Neurosurg Spine. 2017;26(2):158-162. doi:10.3171/2016.7.SPINE 16448

31. Yagi M, Patel R, Boachie-Adjei O. Complications and unfavorable clinical outcomes in obese and overweight patients treated for adult lumbar or thoracolumbar scoliosis with combined anterior/posterior surgery. J Spinal Disord Tech. 2015;28(6):E368-376. doi:10.1097/ BSD.0b013e3182999526

32. Olsen MA, Nepple JJ, Riew KD, et al. Risk factors for surgical site infection following orthopaedic spinal operations. J Bone Joint Surg Am. 2008;90(1):62-69. doi:10.2106/JBJS.F.01515

33. Abdallah DY, Jadaan MM, McCabe JP. Body mass index and risk of surgical site infection following spine surgery: a meta-analysis. Eur Spine J. 2013;22(12):2800-2809. doi:10.1007/s00586-013-2890-6 
34. Oldridge NB, Yuan Z, Stoll JE, Rimm AR. Lumbar spine surgery and mortality among medicare beneficiaries, 1986. Am J Public Health. 1994;84(8):1292-1298. doi:10.2105/AJPH.84.8.1292

35. Benz RJ, Ibrahim ZG, Afshar P, Garfin SR. Predicting complications in elderly patients undergoing lumbar decompression. Clin Orthop Relat Res. 2001;384:116-121. doi:10.1097/00003086-200103000-00 014

36. Okuda S, Oda T, Miyauchi A, Haku T, Yamamoto T, Iwasaki M. Surgical outcomes of posterior lumbar interbody fusion in elderly patients. J Bone Joint Surg Am. 2006;88a(12):2714-2720. doi:10. 2106/JBJS.F.00186

37. Arinzon ZH, Fredman B, Zohar E, et al. Surgical management of spinal stenosis: a comparison of immediate and long term outcome in two geriatric patient populations. Arch Gerontol Geriatr. 2003;36 (3):273-279. doi:10.1016/S0167-4943(02)00172-3
38. Rihn JA, Hilibrand AS, Zhao W, et al. Effectiveness of surgery for lumbar stenosis and degenerative spondylolisthesis in the octogenarian population: analysis of the Spine Patient Outcomes Research Trial (SPORT) data. J Bone Joint Surg Am. 2015;97(3):177-185. doi:10. 2106/JBJS.N.00313

39. Kilinçer C, Steinmetz MP, Sohn MJ, Benzel EC, Bingaman W. Effects of age on the perioperative characteristics and short-term outcome of posterior lumbar fusion surgery. J Neurosurg (Spine). 2005;3(1):34-39. doi:10.3171/spi.2005.3.1.0034

40. Deyo RA, Cherkin DC, Loeser JD, Bigos SJ, Ciol MA. Morbidity and mortality in association with operations on the lumbar spine. The influence of age, diagnosis, and procedure. J Bone Joint Surg Am. 1992;74(4):536-543. doi:10.2106/00004623-199274040-00009
Clinical Interventions in Aging

\section{Publish your work in this journal}

Clinical Interventions in Aging is an international, peer-reviewed journal focusing on evidence-based reports on the value or lack thereof of treatments intended to prevent or delay the onset of maladaptive correlates of aging in human beings. This journal is indexed on PubMed Central, MedLine, CAS, Scopus and the Elsevier
Dovepress

Bibliographic databases. The manuscript management system is completely online and includes a very quick and fair peer-review system, which is all easy to use. Visit http://www.dovepress.com/ testimonials.php to read real quotes from published authors. 